\title{
Vibration Analysis of Grid-Stiffened Circular Cylindrical Shells with Full Free Edges
}

\author{
J. E. Jam, Ph. D. \\ M. Yusef Zadeh, Ph. D. Res. Scientist \\ H. Taghavian, M. Sc. \\ B. Eftari, M. Sc. \\ Composite Materials and Technology Center, Tehran, IRAN
}

\begin{abstract}
Free vibration of grid stiffened circular cylindrical shells is investigated based on the first Love's approximation theory using Galerkin method. Full free edges are considered for boundary conditions. An equivalent stiffness model (ESM) is used to develop the analytical solution of the grid stiffened circular cylindrical shell. The effect of helical stiffeners orientation and some of the geometric parameters of the structure have been shown. The accuracy of the analysis has been examined by comparing results with those available in the literature and finite element approach.
\end{abstract}

Keywords: Free vibration; Grid Structure; Cylindrical Shells; Stiffener; Galerkin Method

\section{INTRODUCTION}

Grid stiffened cylindrical shells are applicable in many industries such as aerospace industries. Stiffened cylindrical shells play a big role in aerospace industries in fuselage and fuel tank applications. This has resulted in an extensive research work in the field of cylinders with stiffening structures [1-8].

Grid stiffened cylindrical shells are widely used in engineering fields. These structures are subjected to external dynamic loads. These external dynamic loads can cause the undesirable resonance and it can lead to fatigue. Moreover, dynamic characteristics must be used on design of structure because only vibration (not fatigue) could severely damage the sensitive equipment in airplanes, launch vehicles and etc. Therefore, it is essential to understand the dynamic behavior of these structures. Theoretical methods of analyzing the grid stiffened structures are classified into two main types, depending upon whether the stiffeners are treated by averaging their properties over the shell surface to conventional materials or by considering them as discrete elements. The first method, so-called smeared stiffener theory, is particularly applicable only when large numbers of stiffeners are closely and evenly spaced. The second method, so-called discrete stiffener theory, is more general as it can accommodate any stiffener distribution. Numerous researches have been developed to study the vibrational behavior of stiffened cylindrical shells. Mustafa and Ali [9] predicted natural frequencies for the stiffened cylindrical shells using the Rayleigh-Ritz procedure. In this procedure they used only one term in assuming the displacement functions satisfying the simply supported boundary condition. One-term approximation is sufficient for the analysis of the cylindrical shells with simply supported boundary condition. However, it can lead to much error to obtain the exact solution of stiffened shells with any other boundary conditions. Yang and Zhou [10] presented the transfer function method to analyze the ringstiffened shell. Lee and Kim [11, 12] investigated the effect of rotation speeds and boundary conditions on the frequencies for the orthogonally stiffened composite cylindrical shells treating the materials of stiffeners as equivalent isotropic. The mentioned papers were, however, limited to the shells with the uniform dimensional and evenly spaced stiffeners. In fact, nonuniform dimensional and unevenly spaced stiffeners are used much more in structural reinforcements. Wang et al. [13] solved the free vibration problem for the isotropic cylindrical shells with varying ring-stiffener distribution using the extended Ritz method. Egle and Sewall [14], in different boundary conditions, have analyzed the effect of stiffeners on natural frequencies of stiffened cylindrical shells. In this research, stiffeners are considered as discrete elements, energy method and Hamilton principle are used to obtain equations of motion. Rinehart and Wang [15] have studied the changes in natural frequencies of cylindrical shells affected by stringers stiffeners, based on Vlasov thin walled beam theory. By both, considering the stiffeners as discrete elements and using energy method, they have obtained the equations of motion.

Unlike the previous study, the vibrations of stiffened cylindrical shells with grid structure under full free boundary conditions are analyzed in this paper. The stiffness matrix of the whole structure is determined by stiffness matrix of grid structures. Then, equilibrium equations are considered based 
on the classical shell theory. Strain-displacement relations are written based on the first approximation of Love theory and then by replacement in stress-strain relations, equilibrium equations based on displacement parameters are obtained. After simplification of equilibrium equations, the shell frequency equation is obtained by using Galerkin method. Finally, according to the following assumptions, the effect of stiffener geometry and mass of grid stiffened cylindrical shell on natural frequencies is presented:

1. The thickness of ribs is small compared with length of the ribs. So the transverse strain of stiffeners is much smaller than that of longitudinal strain and can be negligible.

2. The strain is uniform across the cross-sectional area of the stiffeners. Hence, a uniform stress distribution is assumed across the cross-sectional area of the stiffeners.

3. The load on the stiffener/shell is transferred through shear forces between the stiffeners and shell.

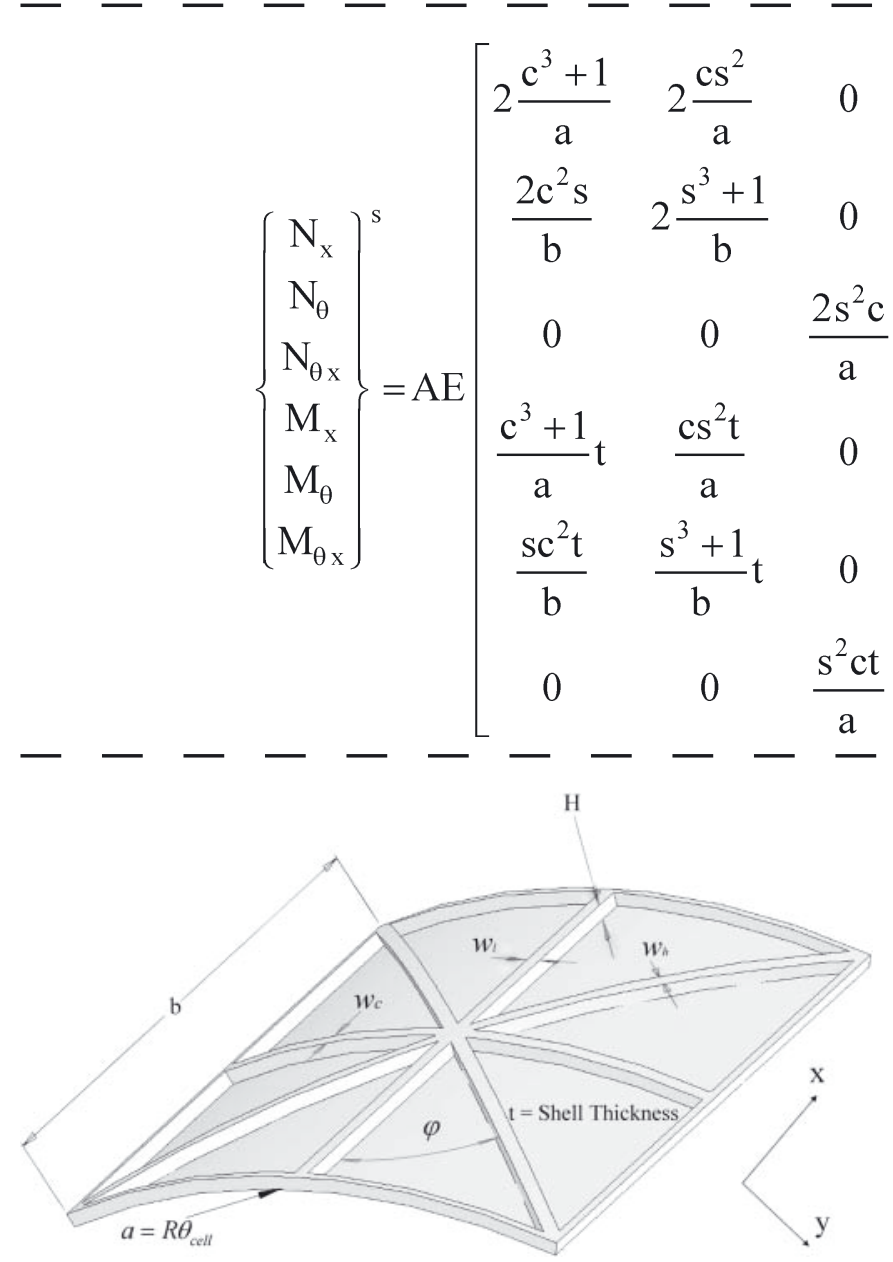

Fig. 1. Grid stiffener and shell design parameters

The above matrix elements are the functions of the strain and curvature parameters of the shell. We denote these stiffness parameters by $\mathrm{A}^{\mathrm{s}}$, $\mathrm{B}^{\mathrm{s}}$ and $\mathrm{D}^{\mathrm{s}}$ which corresponds to the extensional, coupling and bending matrices, respectively. Here, the superscript $s$ stands for stiffener. By the matrix summation of force and moment, coming from the stiffener Grid structure and cylindrical shell, the force and the moment of the whole structure will be obtained.

$$
\left[\begin{array}{l}
N \\
M
\end{array}\right]=\left[\begin{array}{l}
N^{s}+N^{s h} \\
M^{s}+M^{s h}
\end{array}\right]
$$

$\mathrm{N}^{\text {sh }}$ and $\mathrm{M}^{\text {sh }}$ are the force and moment contribution of the shell, respectively. Forces and moments, which affect the shell,

\section{ANALYTICAL METHOD}

\section{Equivalent Stiffness Matrix of the Stiffener and Shell}

To calculate the natural frequencies of the whole structures, first, the stiffness matrix of grid structures must be determined. This matrix is composed of three separated matrices $\mathrm{A}^{\mathrm{s}}, \mathrm{B}^{\mathrm{s}}$ and $\mathrm{D}$ s which can be explained like below:

$$
\left[\begin{array}{l}
N \\
M
\end{array}\right]^{s}=\left[\begin{array}{ll}
A^{s} & B^{s} \\
B^{s} & D^{s}
\end{array}\right]\left[\begin{array}{l}
\varepsilon^{0} \\
k
\end{array}\right]
$$

Based on geometrical variables of grid structures which presented in Fig. 1, stiffness matrix of grid structures can be obtained as below [16]:

$$
\left.\begin{array}{ccc}
\frac{c^{3}+1}{a} t & \frac{c^{2}}{a} t & 0 \\
\frac{c^{2} s t}{b} & \frac{s^{3}+1}{b} t & 0 \\
0 & 0 & \frac{s^{2} c t}{a} \\
\frac{c^{3}+1}{2 a} t^{2} & \operatorname{cs}^{2} \frac{t^{2}}{2 a} & 0 \\
\operatorname{sc}^{2} \frac{t^{2}}{2 b} & \left(s^{3}+1\right) \frac{t^{2}}{2 b} & 0 \\
0 & 0 & s^{2} \frac{t^{2}}{2 a}
\end{array}\right]
$$

relate to the occurred strain by stiffness matrix $\overline{\mathrm{A}^{\text {sh }},}, \overline{\mathrm{B}^{\text {sh }}}$ and $\overline{\mathrm{D}^{\text {sh }}}$. Based on shell mechanical properties, these matrices are:

$$
\begin{gathered}
\mathrm{A}_{\mathrm{ij}}^{\mathrm{sh}}=\frac{\mathrm{Et}}{1-v^{2}}\left[\begin{array}{ccc}
1 & v & 0 \\
v & 1 & 0 \\
0 & 0 & \frac{1-v}{2}
\end{array}\right] \mathrm{B}_{\mathrm{ij}}^{\mathrm{sh}}=[0] \\
\mathrm{D}_{\mathrm{ij}}^{\mathrm{sh}}=\frac{\mathrm{Et}^{3}}{12\left(1-v^{2}\right)}\left[\begin{array}{ccc}
1 & v & 0 \\
v & 1 & 0 \\
0 & 0 & \frac{1-v}{2}
\end{array}\right] \mathrm{i}, \mathrm{j}=1,2,6
\end{gathered}
$$

Substituting the force and moment expressions for the stiffener network from Eq. 2, and the force and moment expressions for the shell from Eq. 4, the total structure constitutive equation given by Eq. 5 results:

$$
\left[\begin{array}{l}
\mathrm{N} \\
\mathrm{M}
\end{array}\right]=\left[\begin{array}{cc}
\mathrm{A}^{\mathrm{s}}+\mathrm{A}^{\mathrm{sh}} & \mathrm{B}^{\mathrm{s}}+\mathrm{B}^{\mathrm{sh}} \\
\mathrm{B}^{\mathrm{s}}+\mathrm{B}^{\mathrm{sh}} & \mathrm{D}^{\mathrm{s}}+\mathrm{D}^{\mathrm{sh}}
\end{array}\right]\left[\begin{array}{l}
\mathrm{e}^{0} \\
\mathrm{k}
\end{array}\right]
$$

\section{Formulation}

The cylindrical shell under consideration is with constant thickness $t$, radius $\mathrm{R}$ and length $\mathrm{L}$. The reference surface of the shell is taken to be at its middle surface where an orthogonal coordinate system $(\mathrm{x}, \theta, \mathrm{z})$ is fixed. As shown in Fig. 2 , the 
$\mathrm{x}$ axis is taken in the axial direction of the shell, where the $\theta$ and $\mathrm{z}$ axises are in the circumferential and radial directions of the shell, respectively. The displacements of the shell are defined by $\mathrm{u}, \mathrm{v}, \mathrm{w}$ in the $\mathrm{x}, \theta, \mathrm{z}$ directions respectively.

The equations of motion for a cylindrical shell can be written by the Love theory as:

$$
\left[\begin{array}{ccc}
\mathrm{L}_{11} & \mathrm{~L}_{12} & \mathrm{~L}_{13} \\
\mathrm{~L}_{21} & \mathrm{~L}_{22} & \mathrm{~L}_{23} \\
\mathrm{~L}_{31} & \mathrm{~L}_{32} & \mathrm{~L}_{33}
\end{array}\right]\left\{\begin{array}{l}
\mathrm{u} \\
\mathrm{v} \\
\mathrm{w}
\end{array}\right\}=\left\{\begin{array}{l}
0 \\
0 \\
0
\end{array}\right\}
$$

where:

$\mathrm{L}_{\mathrm{ij}}(\mathrm{i}, \mathrm{j}=1,2,3)-$ the differential operators with respect to $\mathrm{x}$ and $\theta$.

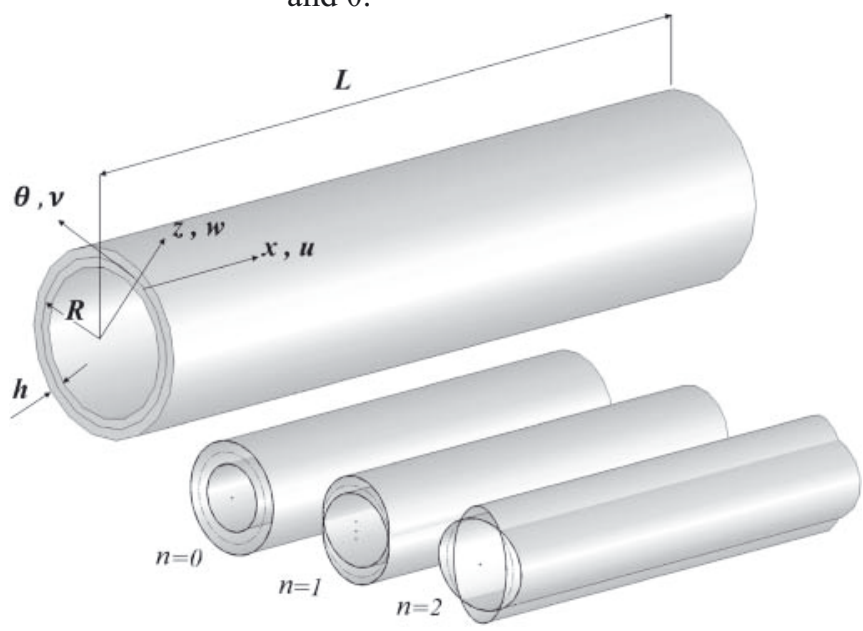

Fig. 2. Co-ordinate system and circumferential modal shape [17]

\section{Boundary Conditions}

Due to the satisfaction of the boundary conditions, the displacement $\mathrm{u}, \mathrm{v}$ and $\mathrm{w}$ can be explained as double Fourier series [19]:

$$
\begin{aligned}
& \mathrm{u}(\mathrm{x}, \theta, \mathrm{t})=\sum_{\mathrm{m}} \sum_{\mathrm{n}} \mathrm{A}_{\mathrm{mn}} \frac{\partial \varphi_{\mathrm{u}}(\mathrm{x})}{\partial \mathrm{x}} \cos (\mathrm{n} \theta) \cos (\omega \mathrm{t}) \\
& \mathrm{v}(\mathrm{x}, \theta, \mathrm{t})=\sum_{\mathrm{m}} \sum_{\mathrm{n}} \mathrm{B}_{\mathrm{mnv}} \varphi(\mathrm{x}) \sin (\mathrm{n} \theta) \cos (\omega \mathrm{t}) \\
& \mathrm{w}(\mathrm{x}, \theta, \mathrm{t})=\sum_{\mathrm{m}} \sum_{\mathrm{n}} \mathrm{C}_{\mathrm{mnv}} \varphi(\mathrm{x}) \cos (\mathrm{n} \theta) \cos (\omega \mathrm{t})
\end{aligned}
$$

In recent equations, $\mathrm{A}_{\mathrm{mn}}, \mathrm{B}_{\mathrm{mn}}$ and $\mathrm{C}_{\mathrm{mn}}$ are coefficients of natural modes' shape, which obtained from solving free vibration. For solving free vibrations, $T_{m n}(t)=e^{\omega}{ }_{m n}{ }^{t}$ is considered as a function of time, $\mathrm{m}$ is the number of axial half-wavelength, $\mathrm{n}$ is the number of circumferential half-wavelength and $\omega_{\mathrm{mn}}$ is the natural frequency in mode of mn. To satisfy boundary conditions, axial and circumferential functions are explained as below:

$$
\left\{\begin{array}{l}
\varphi_{\mathrm{i}}(\mathrm{x})=\alpha_{1} \cosh \left(\frac{\lambda_{\mathrm{m}} \mathrm{x}}{\mathrm{L}}\right)+\alpha_{2} \cos \left(\frac{\lambda_{\mathrm{m}} \mathrm{x}}{\mathrm{L}}\right)-\sigma_{\mathrm{m}}\left(\alpha_{3} \sinh \left(\frac{\lambda_{\mathrm{m}} \mathrm{x}}{\mathrm{L}}\right)-\alpha_{4} \sin \left(\frac{\lambda_{\mathrm{m}} \mathrm{x}}{\mathrm{L}}\right)\right)(\mathrm{i}=\mathrm{u}, \mathrm{v}, \mathrm{w}) \\
\phi_{\mathrm{v}}(\theta)=\sin (\mathrm{n} \theta) \quad \phi_{\mathrm{u}}(\theta)=\phi_{\mathrm{w}}(\theta)=\cos (\mathrm{n} \theta)
\end{array}\right.
$$

where:

\section{Free Vibration Analysis}

Using Galerkin method and substituting Eq. 7 into Eq. 6, it can be written as:

$$
\left[\begin{array}{lll}
c_{11} & c_{12} & c_{13} \\
c_{21} & c_{22} & c_{23} \\
c_{31} & c_{32} & c_{33}
\end{array}\right]\left\{\begin{array}{l}
A_{m n} \\
B_{m n} \\
D_{m n}
\end{array}\right\}=0
$$

$\mathrm{C}_{\mathrm{ij}}(\mathrm{i}, \mathrm{j}=1,2,3)$ - the parameters from the $\mathrm{L}_{\mathrm{ij}}$ after they are operated with the $\mathrm{x}$ and $\theta$.

For non-trivial solutions, one sets the determinant of the characteristic matrix in Eq. 9 to zero:

$$
\operatorname{det}\left(\mathrm{C}_{\mathrm{ij}}\right)=0(\mathrm{i}, \mathrm{j}=1,2,3)
$$

So the frequency equation can be obtained as:

$$
\beta_{1} \omega^{6}+\beta_{2} \omega^{4}+\beta_{3} \omega^{2}+\beta_{4}=0
$$

where:

$\beta_{i}(i, j=1,2,3)-$ the coefficients of Eq. 10 .

Solving Eq. 11, one obtains three positive roots and three negative roots. The three positive roots are the angular natural frequencies of the cylindrical shell in the axial, circumferential and radial directions. The lowest of the three positive roots represents the flexural vibration, and the other two are in-plane vibrations.

\section{NUMERICAL RESULTS AND DISCUSSION}

Numerical implementation of the present analysis was performed using general-purpose computation package

\begin{tabular}{|c|c|c|c|c|}
\hline $\mathbf{m}$ & $\mathbf{n}$ & Reference [17] & Present & Difference $(\%)$ \\
\hline \multirow{5}{*}{1} & 7 & 251.4 & 267.9 & 6.56 \\
\hline & 8 & 243.5 & 243.0 & 0.20 \\
\hline & 9 & 257.1 & 252.4 & 1.82 \\
\hline & 10 & 280.2 & 284.5 & 1.53 \\
\hline & 11 & 340.3 & 331.2 & 2.67 \\
\hline
\end{tabular}
MATLAB. To check the accuracy of the present analysis, the results obtained are compared with those in the [17]. A comparison of the values of the frequency of a free vibrating cylindrical shell with the F-F boundary conditions is given in Table 1. Tab. 1. Comparison of values of the natural frequency $\omega_{n}$ for a cylindrical
shell with $F-F$ supported boundary conditions $m=1 ; R / h=374 ; L / R=2.63 ; h=0.6477 \mathrm{~mm}$ $E=70 \mathrm{GPA} ; v=0.3 ; \rho=2700 \mathrm{Kg} / \mathrm{m}^{3}$
In above equations $\alpha_{i}$ are constant coefficients which determined according to boundary conditions. $\lambda_{\mathrm{m}}$ is the root of non-linear equations and $\sigma_{\mathrm{m}}$ is the dependant parameter on $\lambda_{\mathrm{m}}$ which obtained according to boundary conditions. Free-Free supported conditions can be defined as below:

$$
\frac{\partial^{2} \varphi(x)}{\partial x^{2}}=\frac{\partial^{3} \varphi(x)}{\partial x^{3}}=0
$$

In the parameter, $\mathrm{E}$ is Young's modulus of elasticity, $v$ is the Poisson ratio, $\rho$ is the density, $\mathrm{R}$ is the radius and $\omega$ is the frequency. The comparisons are carried out for the parameter of $\mathrm{L} / \mathrm{R}=2.63$ and for the cases of $\mathrm{R} / \mathrm{h}=374$ and $\mathrm{t}=6.477 \times 10^{-4} \mathrm{~m}$. Using the method outlined earlier, numerical results are obtained for the six model of grid-stiffened cylinder with four families of ribs and geometric and mechanical parameters given in Tables 2 and 3. 
Tab. 2. Dimensions of the considered structures ( $\mathrm{mm}, \mathrm{kg}$ )

\begin{tabular}{|c|c|c|c|c|c|c|c|c|c|}
\hline $\mathbf{m}_{\text {тот }}$ & $\mathbf{m}_{\text {stiffener }}$ & $\mathbf{m}_{\text {shell }}$ & $\mathbf{t}_{\text {shell }}$ & $\mathbf{R}$ & $\mathbf{L}$ & $\boldsymbol{\varphi}$ & $\begin{array}{c}\mathbf{w}_{\mathbf{h}}=\mathbf{w}_{\mathbf{c}}= \\
=\mathbf{w}_{\mathbf{l}}=\mathbf{W}\end{array}$ & $\mathbf{H}$ & \\
\hline 19.794 & 3.450 & 16.344 & 5 & 300 & 653 & $30^{\circ}$ & 6 & 6 & Model 1 \\
\hline 21.007 & 4.663 & 16.344 & 5 & 300 & 653 & $30^{\circ}$ & 7 & 7 & Model 2 \\
\hline 25.681 & 9.337 & 16.344 & 5 & 300 & 653 & $30^{\circ}$ & 10 & 10 & Model 3 \\
\hline 36.647 & 20.302 & 16.344 & 5 & 300 & 653 & 30 ș & 15 & 15 & Model 4 \\
\hline 20.944 & 4.430 & 16.344 & 5 & 300 & 640 & 45 ş & 6 & 6 & Model 5 \\
\hline 22.505 & 6.161 & 16.344 & 5 & 300 & 653 & 60 ş & 6 & 6 & Model 6 \\
\hline
\end{tabular}

Tab. 3. Mechanical properties of the models (Aluminum)

\begin{tabular}{|c|c|c|}
\hline Modulus of elasticity & Poisson's ratio & Density \\
\hline $\mathrm{E}(\mathrm{GPa})$ & $v$ & $\rho \mathrm{kg} / \mathrm{m}^{3}$ \\
\hline 70 & 0.3 & 2700 \\
\hline
\end{tabular}

The obtained results are compared to the solution of the same problem when the considered structures are modeled with a finite element analysis package ANSYS. One of the generated mesh by this package is shown in Fig. 3.

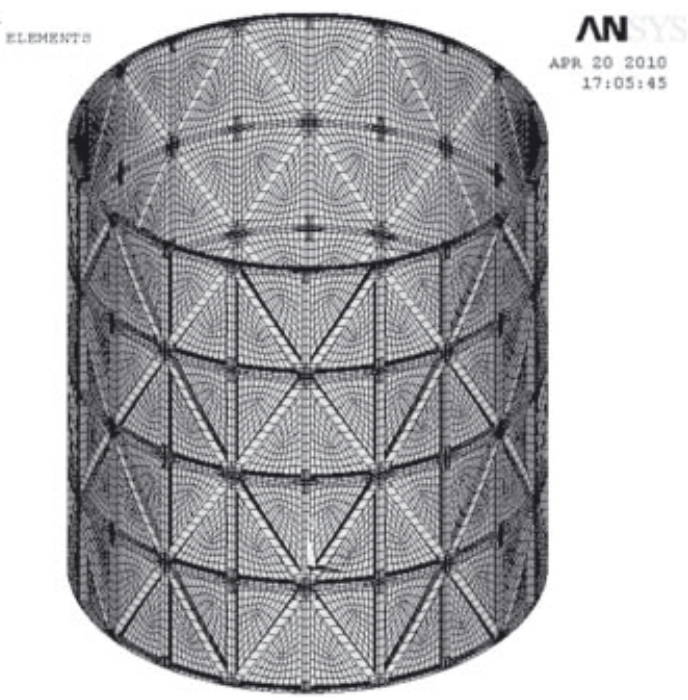

Fig. 3. The mesh generated for a grid stiffened cylindrical shell using ANSYS

Based on a technical report [18], natural frequencies of a grid-stiffened shell can be approximated by equivalent of thickness. In this method, a conventional shell with the same weight as grid part is predicted. An equivalent shell will be produced by the replacement of this shell with grid part. The

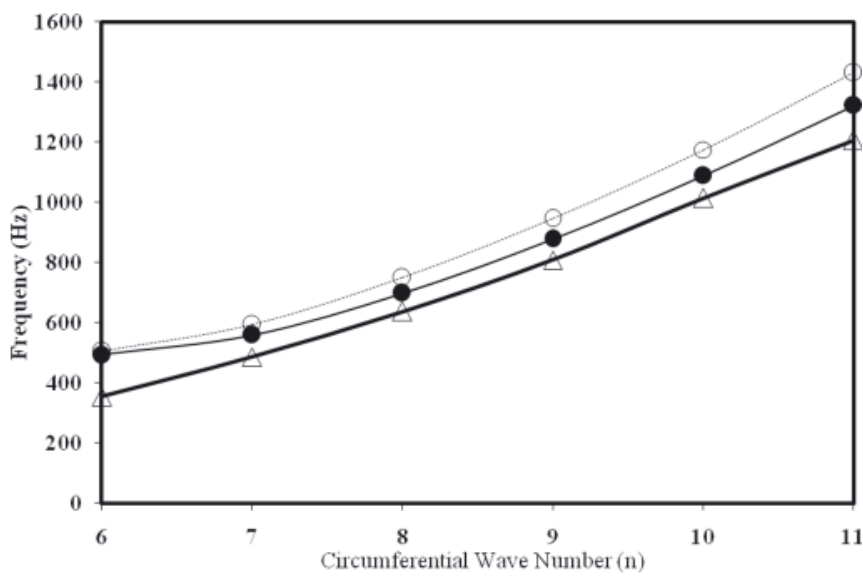

Fig. 4. Values of natural frequency for Model (1) with Free-Free boundary conditions in three methods. $\triangle$ FEM; • Present Method; ○ ETM (Equivalent Thickness Method); $m=1$ obtained frequencies of this equivalent shell can be a proper approximation for natural frequencies of the main structure. In Figs. 4-9, a comparison between the results obtained by ETM (Equivalent Thickness Method), FEM and present method is presented. These figures have shown that the present method gives more exact answers than ETM.

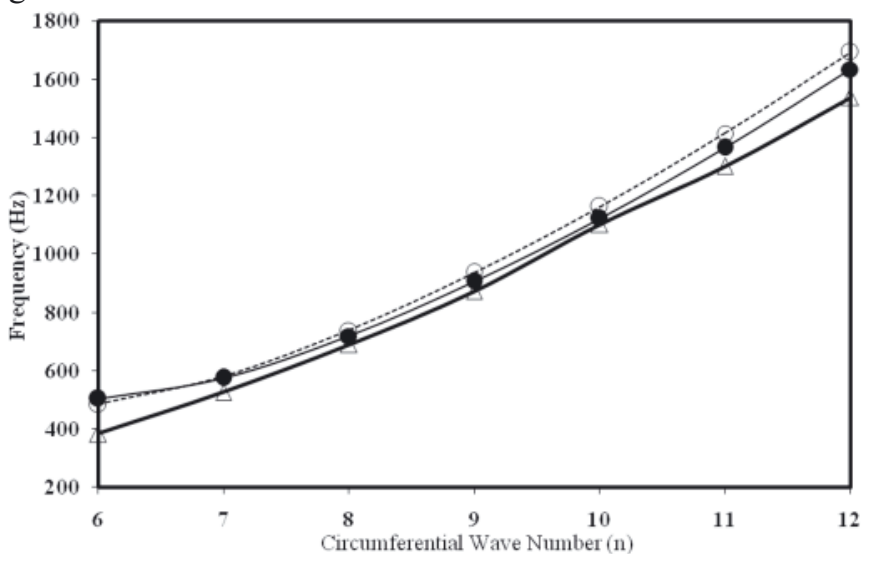

Fig. 5. Values of natural frequency for Model (2) with Free-Free boundary conditions in three methods. $\triangle$ FEM; $\bullet$ Present Method; $\circ$ ETM (Equivalent

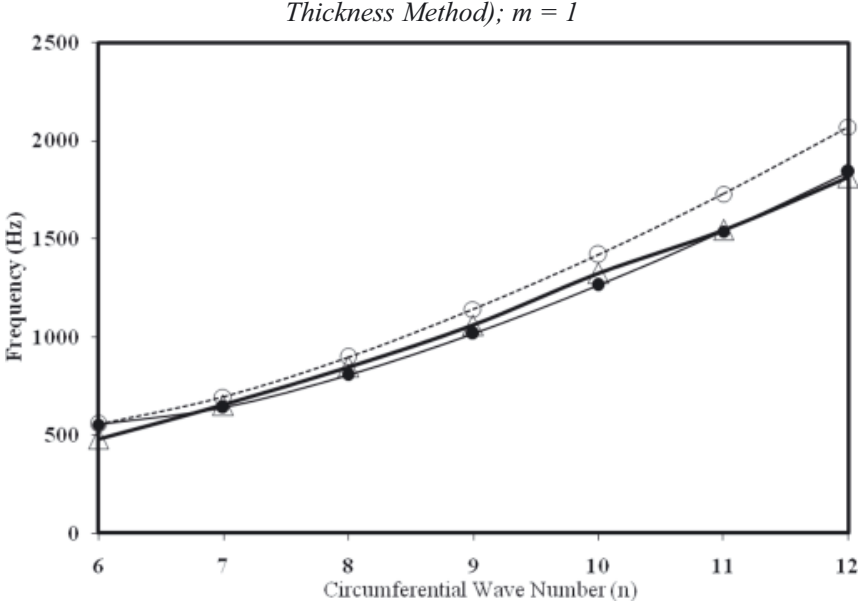

Fig. 6. Values of natural frequency for Model (3) with Free-Free boundary conditions in three methods. $\triangle$ FEM; $\bullet$ Present Method; $\circ$ ETM (Equivalent Thickness Method); $m=1$

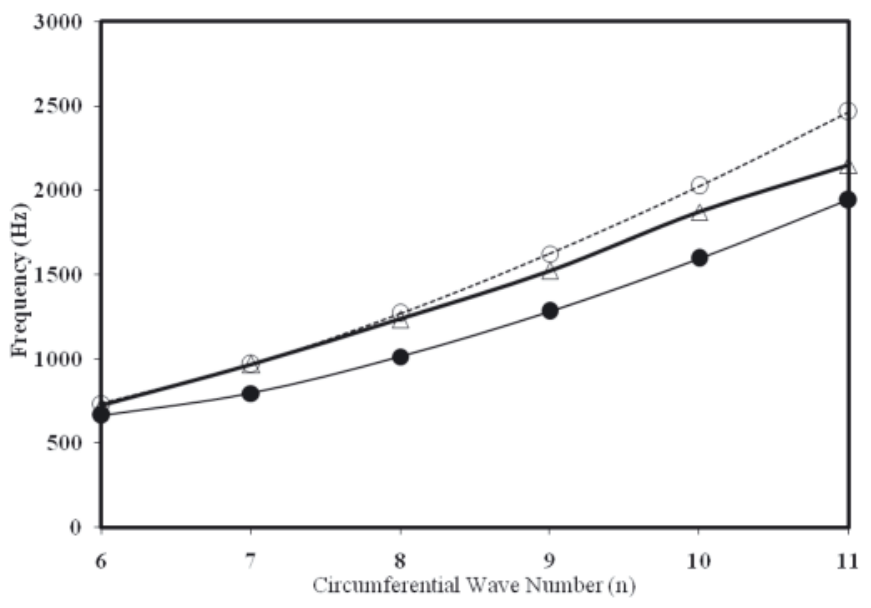

Fig. 7. Values of natural frequency for Model (4) with Free-Free boundary conditions in three methods. $\triangle$ FEM; • Present Method; O ETM (Equivalent Thickness Method); $m=1$

Fig. 10 shows the changes relative to natural frequencies of six predicted models, according to the angle of helical ribs. As shown in this figure, when the angle of helical rib increases, the amount of natural frequencies of structures will be increased. 


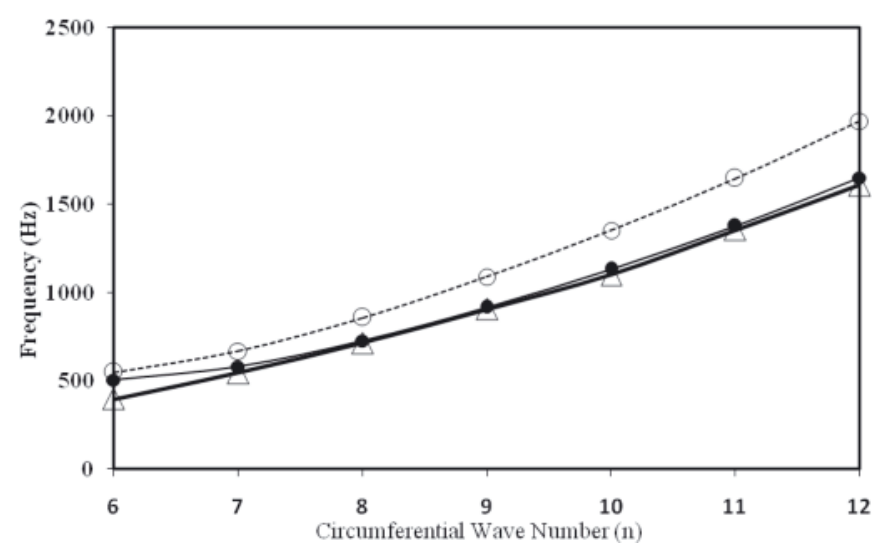

Fig. 8. Values of natural frequency for Model (5) with Free-Free boundary conditions in three methods. $\triangle$ FEM; • Present Method; ○ ETM (Equivalent

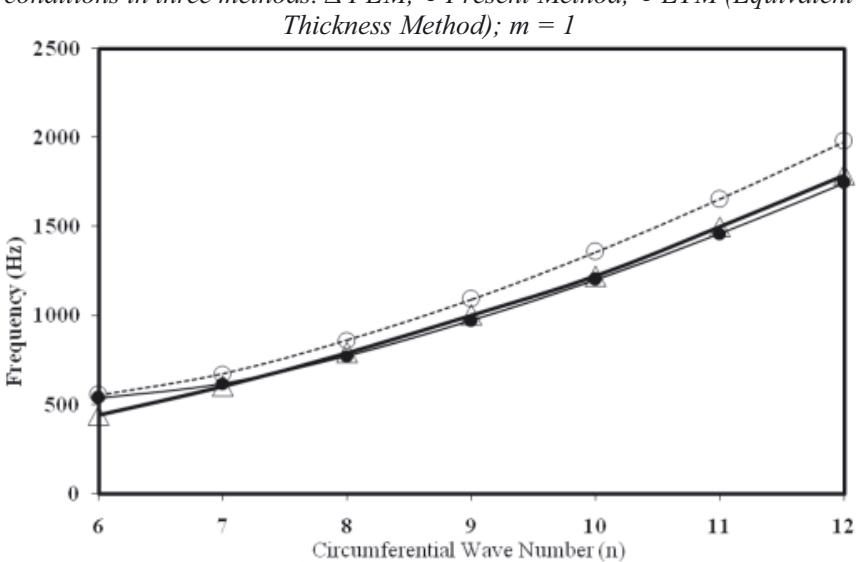

Fig. 9. Values of natural frequency for Model (6) with Free-Free boundary conditions in three methods. $\triangle$ FEM; • Present Method; ○ ETM (Equivalent

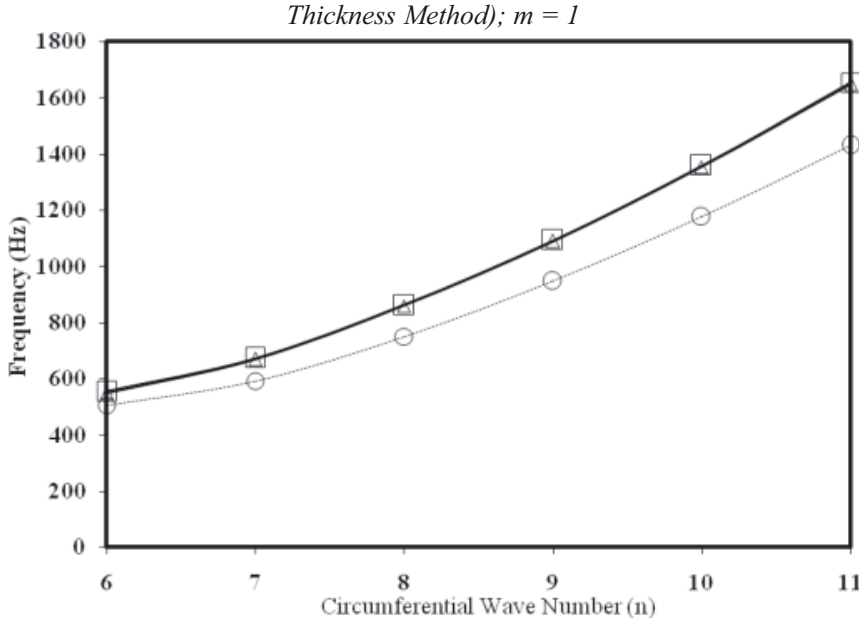

Fig. 10. Comparison of natural frequencies of three predicted models according to the angle of helical ribs. $\circ \varphi=30$ (Model 1); $\Delta \varphi=45$ (Model

$$
\text { 5); } \square \varphi=60 \text { (Model 6); } m=1
$$

Note: In this comparison Model 5 is smaller length than the remaining ones (about 2\%). According to difference between configurations of models, the resulted value from FEM modeling is the minimum height discrepancy can be obtained.

\section{CONCLUSION}

The article has presented the analysis of grid stiffened cylindrical shell using Galerkin method. Comparison of the results by the present method and numerical finite element method was carried out. The six finite element models for grid stiffened cylindrical shell were created. The shell was fully free-free at both ends. The second six natural frequencies were obtained with the ANSYS. These results were compared with the present method and the agreement between them was good. Based on comparisons of the mentioned method, it is concluded that the present method is more convenient, more effective and more accurate.

\section{BIBLIOGRAPHY}

1. Helms J. E., Li G., Smith B. H.: Analysis of grid stiffened cylinders, ASME/ETCE, USA, 2001.

2. Navin J., Norman F. K., Damodar R.: Formulation of an improved smeared stiffener theory of buckling analysis of gridstiffened composite panels, NASA Technical Memorandum 110162, USA, 1995.

3. Phillips J. L., Gurdal Z.: Structural analysis and optimum design of geodesically stiffened composite panels, Report NASA CCMS-90-50 (VPI-E-90-08), Grant NAG-1-643, USA, 1990.

4. Brush D. O., Almroth B. O.: Buckling of bars, plates, and shells, McGraw-Hill, New York, 1975.

5. Bruhn E. F.: Analysis and design of flight vehicle structures, Jacobs Publishing, Carmel, 1973.

6. Ramm E.: Buckling of shells, Springer, Berlin,1982.

7. Gerdon G., Gurdal Z.: Optimal design of geodesically stiffened composite cylindrical shells, Journal of AIAA, 23(11) (1985), 1753-61.

8. Troisky M.S.: Stiffened plates, bending, stability and vibration, Elsevier, Amsterdam, 1976.

9. B. A. J. Mustafa and R. Ali: An energy method for free vibration analysis of stiffened circular cylindrical shells, Computers and Structures 32 (1989), 355-363.

10.B. Yang and J. Zhou: Analysis of ring-stiffened cylindrical shells, Journal of Applied Mechanics 62 (1995), 1005-1014.

11.Y. S. Lee and Y. W. Kim: Vibration analysis of rotating composite cylindrical shells with orthogonal stiffeners, Computers and Structures, 69 (1998), 271-281.

12.Y. S. LEE and Y.W. KIM: Effect of boundary conditions on natural frequencies for rotating composite cylindrical shells with orthogonal stiffeners, Advanced in Engineering Software 30 (1999), 649-655.

13.M. Wang, S. Swaddiwudhipong and J. Tian: Ritz method for vibration analysis of cylindrical shells with ring stiffeners, Journal of Engineering Mechanics 123 (1997), 134-142.

14.D. M. Egle, J. L. Sewall: An analysis of the free vibration of orthogonally stiffened cylindrical shells with stiffener separated as discrete elements, AIAA Journal 3 (1968), 518 26.

15.S. A. Rinehart, J. T. S Wang: Vibration of Simply Supported Cylindrical Shells with Longitudinal Stiffeners, Journal of Sound and Vibration 24 (1972), 151-163.

16.Samuel Kidane, Guoqiang Li, Jack Helms, Su-Seng Pang, Eyassu Woldesenbet: Buckling Load Analysis of Grid Stiffened Composite Cylinders, Journal of Composites, PartB 34 (2003), $1-9$.

17.Arthur Leissa: Vibration of Shells. Columbus, Acoustical Society of America, Ohio, 1993.

18. Hassan Mahfuz: Final Report on Innovative Manufacturing and Structural Analysis of Composite Isogrid Structures for Space Applications, AFRL-SR-AR-TR-04, USA, 2004.

19.M. M. Najafizadeh, M. R. Isvandzibaei: Vibration of Functionally Graded Cylindrical Shells Based on Higher Order Shear Deformation Plate Theory With ring Support, Acta Mech Journal, 191 (2007), 75-91.

\section{CONTACT WITH THE AUTHORS}

\author{
J. E. Jam, Ph. D. \\ tel.: $98-21-22952286$ \\ fax: 98-21-22936578
}

e-mail address: jejam@mail.com

M. Yusef Zadeh, Ph. D. Res. Scientist

H. Taghavian, M. Sc.

B. Eftari, M. Sc.

Composite Materials and Technology Center, MUT, Tehran, IRAN 